\title{
COMPARISON OF THE CRYSTALLIZATION PROCESSES IN SOME SOFT AND HARD MAGNETIC MATERIALS
}

\author{
B. Bhanu Prasad ${ }^{1}$, N. Rajya Lakshmi ${ }^{2}$, M.D.V. Sri Lalitha ${ }^{3}$ \\ ${ }^{l}$ M.V.S.R. Engineering College, Nadergul, Hyderabad - 501510 \\ ${ }^{2}$ M.V.S.R. Engineering College, Nadergul, Hyderabad - 501510 \\ ${ }^{3}$ M.V.S.R. Engineering College, Nadergul, Hyderabad-501 510
}

\begin{abstract}
The crystallization process and phase transformations in amorphous $\mathrm{Fe}_{68.8} \mathrm{Si}_{18.6} B_{9.5} \mathrm{Nb}_{2.6} \mathrm{Cu}_{0.5}, \quad \mathrm{Fe}_{78} \mathrm{Gd}_{2} \mathrm{~B}_{20}, \mathrm{Fe}_{78} \mathrm{D} \mathrm{y}_{2} \mathrm{~B}_{20}$ and $\mathrm{Fe}_{78} \mathrm{Tm}_{2} \mathrm{~B}_{20}$ alloys have been studied by Differential Scanning Calorimetry (DSC), Scanning Electron Microscopy (SEM), Energy Dispersive Spectroscopy (EDS) and X-Ray Diffration (XRD). DSC of amorphous $\mathrm{Fe}_{68.8} \mathrm{Si}_{18.6} \mathrm{~B}_{9.5} \mathrm{Nb}_{2.6} \mathrm{Cu}_{0.5}$ alloy showed two peaks one at $569^{\circ} \mathrm{C}$ and another at $709^{\circ} \mathrm{C}$ respectively indicating two step crystallization. XRD of the crystallized samples showed the presence of the crystalline phase $\alpha-F e$. The DSC curve of Amorphous $\mathrm{Fe}_{78} \mathrm{Gd}_{2} \mathrm{~B}_{20}$ alloy showed an exothermal peak at $828 \mathrm{~K}$ showing the crystallization of the sample. From the DSC study, the crystallization temperature of $\mathrm{Fe}_{78} \mathrm{Gd}_{2} \mathrm{~B}_{20}$ alloy was found to be $828 \mathrm{~K}$. The lattice parameter ' $a$ ' was found to be $2.8656 \mathrm{~A}^{\circ}$. From the DSC study the crystallization temperature of $\mathrm{Fe}_{78} \mathrm{D} \mathrm{y}_{2} \mathrm{~B}_{20}$ alloy was found to be $828 \mathrm{~K}$. DSC study on amorphous $\mathrm{Fe}_{78} \mathrm{Tm}_{2} \mathrm{~B}_{20}$ alloy showed a sharp peak at $818 \mathrm{~K}$ indicating a phase transformation from amorphous to crystalline in the sample.
\end{abstract}

Keywords: crystallization, $\mathrm{Fe}_{68.8} \mathrm{Si}_{18.6} \mathrm{~B}_{9.5} \mathrm{Nb}_{2.6} \mathrm{Cu}_{0.5}, \mathrm{Fe}_{78} \mathrm{Gd}_{2} \mathrm{~B}_{20}, \mathrm{Fe}_{78} \mathrm{Dy} \mathrm{B}_{2} \mathrm{~B}_{20}$ and $\mathrm{Fe}_{78} \mathrm{Tm}_{2} \mathrm{~B}_{20}$ - ****

\section{INTRODUCTION}

Soft ferromagnetic materials show high saturation induction, low coercivity and high resistivity. Hence,they find industrial applications. Nano-crystallina alloys exhibiting superior soft magnetic bahaviour with the composition known as FINEMET were first derived by Yoshizava et. al[1,2]. Similarly,hard ferromagnetic materials show high saturation and high coercivity with large area of B-H curve called energy product. Thus, RE(Rare Earth) containing alloys (usually Fe-RE-B) obtained in amorphous state by Melt-Spinning technique and substantially annealed, have enhanced magnetic properties, compared to traditional permanent magnets. As the cost is lowered due to the substantial reduction of the rare-earth content, it therefore accounts for a new generation of permanent magnetic materials. Thus, in the present work, a comparison is made in the crystallization process and phase transformations in amorphous $\mathrm{Fe}_{68.8} \mathrm{Si}_{18.6} \mathrm{~B}_{9.5} \mathrm{Nb}_{2.6} \mathrm{Cu}_{0.5}, \mathrm{Fe}_{78} \mathrm{Gd}_{2} \mathrm{~B}_{20}, \mathrm{Fe}_{78} \mathrm{Dy}_{2} \mathrm{~B}_{20}$ and $\mathrm{Fe}_{78} \mathrm{Tm}_{2} \mathrm{~B}_{20}$ alloys by Differential Scanning Calorimetry (DSC), Scanning Electron Microscopy (SEM), Energy Dispersive Spectroscopy (EDS) and X-Ray Diffration (XRD) and the results are discussed.

\section{EXPERIMENTAL}

Amorphous $\quad \mathrm{Fe}_{68.8} \mathrm{Si}_{18.6} \mathrm{~B}_{9.5} \mathrm{Nb}_{2.6} \mathrm{Cu}_{0.5}, \quad \mathrm{Fe}_{78} \mathrm{Gd}_{2} \mathrm{~B}_{20}$, $\mathrm{Fe}_{78} \mathrm{Dy}_{2} \mathrm{~B}_{20}$ and $\mathrm{Fe}_{78} \mathrm{Tm}_{2} \mathrm{~B}_{20}$ alloys have been produced by melt spinning technique. Their thickness is about $30 \mu \mathrm{m}$ and widths vary from $1 \mathrm{~mm}$ to $10 \mathrm{~mm}$. Four probe resistance apparatus was used for resistance measurements. Differential Scanning Calorimeter (DSC) is used to study the crystallization process of the samples at a constant heating rate of $20^{\circ} \mathrm{C}$. A sample of $2.603 \mathrm{mg}$ was taken and used for DSC measurement. Similarly, Scanning Electron
Microscopy (SEM), Energy Dispersive Spectroscopy (EDS) and X-Ray Diffration (XRD) units were used for structure determination and to verify the composition of the materials for as-cast and heated samples.

\section{RESULTS AND DISCUSSION}

To investigate the thermal behavior of the alloy, high temperature DSC was conducted at a heating rate of $20^{\circ} \mathrm{C} / \mathrm{min}$ and the plot is given in the fig 1 . Thus, The DSC of amorphous $\mathrm{Fe}_{68.8} \mathrm{Si}_{18.6} \mathrm{~B}_{9.5} \mathrm{Nb}_{2.6} \mathrm{Cu}_{0.5}$ alloy showed two peaks one at $569^{\circ} \mathrm{C}$ and the other at $709^{\circ} \mathrm{C}$, respectively indicating a two step crystallization in the sample. XRD on the annealed sample showed a single peak showing the presence of a crystalline phase $\alpha$-Fe. The sharpness of the peak increases and grain size increases with increasing annealing temperature. SEM and EDS showed the structure of the completely crystallized sample. Thus, it reveals that the alloy undergoes two stage crystallization reactions at $569.4^{\circ} \mathrm{C}$ and $709^{\circ} \mathrm{C}$. This gives wide temperature interval of $140.2^{\circ} \mathrm{C}$ between two crystallization stages. Observation of two step crystallization is more common in metallic glasses contained more than three elements than in those containing less components. The first broad peak in the present case arises due to (1). Structural relaxation due to a variety of atomic rearrangement and (2). Formation of intermediate metastable phases. The second peak arises due to crystallization as in glass which is a defined nucleation and growth reaction. Broadening also occurs due to kinetic reasons as the kinetics involving structural processes slows down due to the disappearance of free volume during relaxation processes. Samples were heat treated at various temperatures for one hour to investigate the crystallization process and XRD patterns are plotted and shown in fig 2 . 


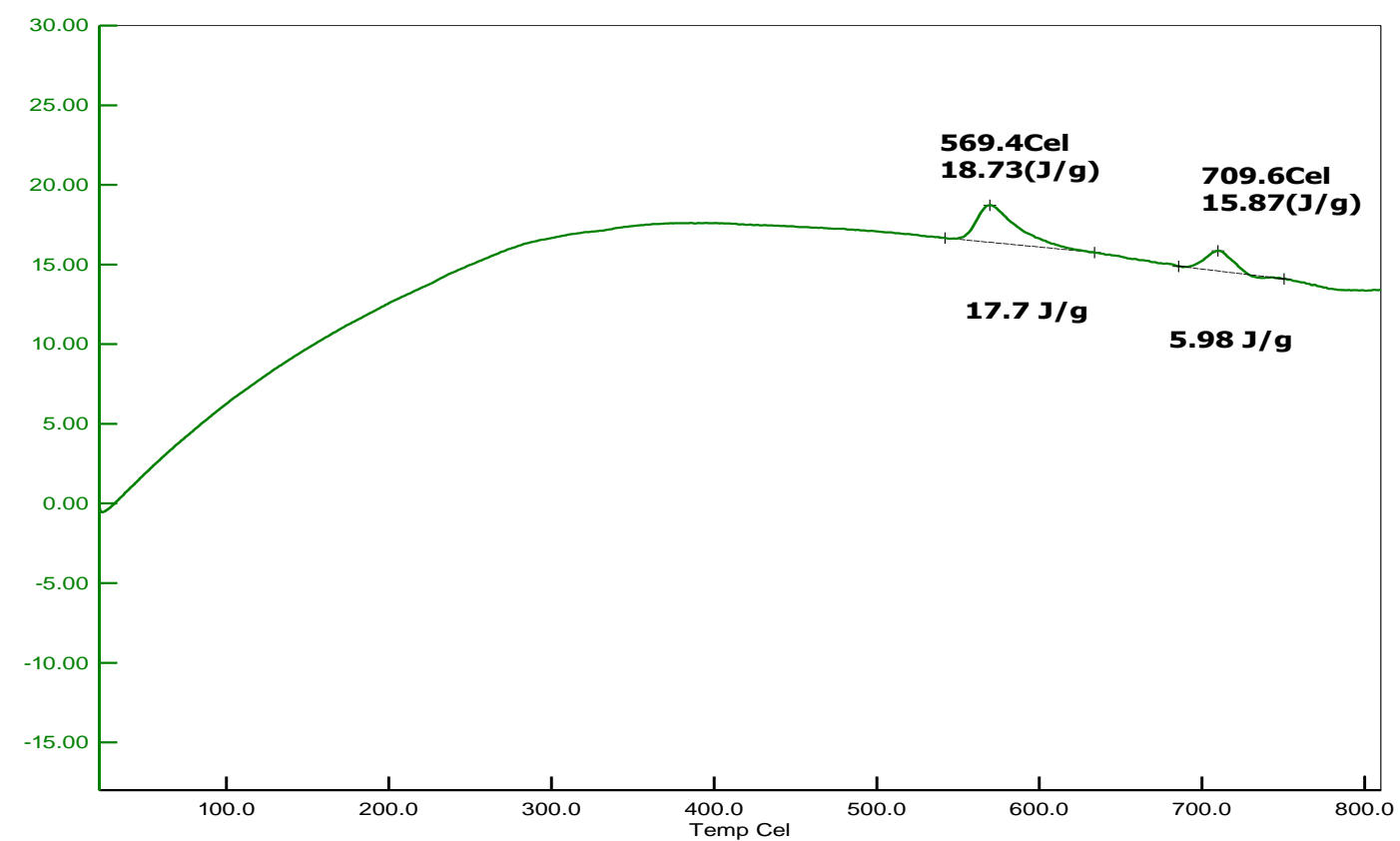

Fig.1 DSC curve of $\mathrm{Fe}_{68.8} \mathrm{Si}_{18.6} \mathrm{~B}_{9.5} \mathrm{Nb}_{2.6} \mathrm{Cu}_{0.5}$ alloy at a heating rate of of $20^{\circ} \mathrm{C} / \mathrm{min}$.

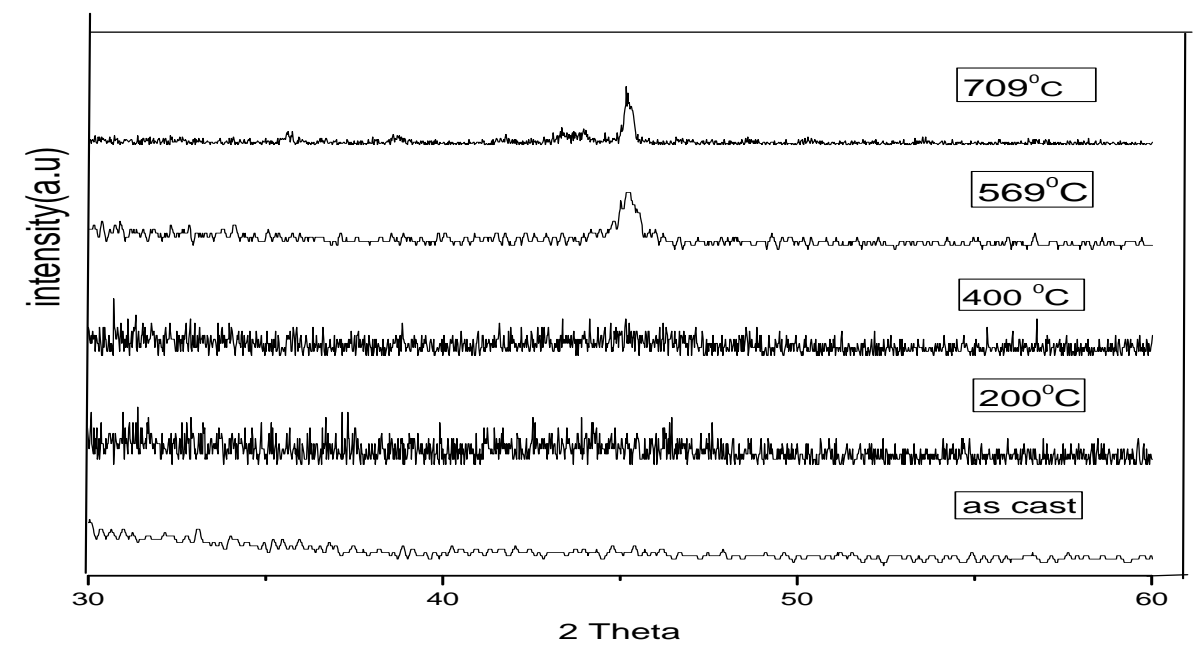

Fig. 2 X-Ray diffraction pattern for the as received and heat treated samples

The XRD pattern of as-cast alloy shown in fig. 2 reveals the amorphous nature of the sample. The XRD pattern of the sample annealed at $200^{\circ} \mathrm{C}$ and $400^{\circ} \mathrm{C}$ for one hour indicates slightly a different behaviour but still can be attributed with no major changes in the amorphous nature. It refers that the crystallization has been not yet started at those temperatures. Sample heat-treated at $569^{\circ} \mathrm{C}$ reveals a peak in the XRD pattern indicating the primary crystallization. We also analysed that the phases obtained at $569^{\circ} \mathrm{C}$ are $\alpha-\mathrm{Fe}$ and $\mathrm{Fe}_{3} \mathrm{Si}$. The formation of $\mathrm{Fe}_{3} \mathrm{Si}$ phase during annealing is attributed to the presence of $\mathrm{Nb}$ clusters that act as nucleation sites due to strong attractive interaction between $\mathrm{Si}$ and $\mathrm{Nb}$ atoms [3]. The sample heat-treated at $709^{\circ} \mathrm{C}$ shows a sharp peak almost in the same position observed for the sample heat-treated at $569^{\circ} \mathrm{C}$. This sharp peak indicates the start of $\mathrm{Fe}_{2} \mathrm{~B}$ phase. Thus the sample heat-treated at $709^{\circ} \mathrm{C}$ shows an increase in the intensity of the peak along with appearance of some new peaks. The increase in the intensity of the peak and decrease in the broadening indicates enhancement in the density and size of $\mathrm{Fe}_{3} \mathrm{Si}$ phase. This suggests that the second stage of crystallization produces mainly $\mathrm{Fe}_{2} \mathrm{~B}$. The crystallite size of $\mathrm{Fe}_{3} \mathrm{Si}$ particles was estimated by X-ray peak using Scherrer equation[4].

$$
\mathrm{D}=\frac{0.94 \lambda}{\cos \theta F W H M}
$$

Where $\lambda$ is the wavelength, $\theta$ is the glancing angle and FWHM is the Full-width at half maximum of reflection. The crystallite size of the annealed sample at $560^{\circ} \mathrm{C}$ is about $18 \mathrm{~nm}$. And the crystallite size of the annealed sample at $700^{\circ} \mathrm{C}$ is about $43 \mathrm{~nm}$. 
A scanning electron microscopy of the sample was taken at room temperature before and after heating and at different resolutions which is shown in fig 3 and fig 4. As a supportive work electron dispersive spectroscopy (EDS) patterns for the as-cast and crystallized sample is shown in fig.5(a) and fig.5(b) and fig.6(a), fig.6(b) respectively. Before heating the sample is amorphous as shown by the SEM photo of Fig 3and EDS photo of Fig 5(a). For the sample which is heated to $1000 \mathrm{~K}$ and cooled, the SEM photo shown in Fig 4 and EDS photo shown in Fig 6(a) indicate the crystallization of the sample. Thus Fig 5(b) shows the EDS spectrum of as received (before heating ) sample. Fig 6(b). shows the EDS spetrum of the crystallized (heated to $1000 \mathrm{~K}$ and cooled) sample showing additional peaks representing the crystalline phases.

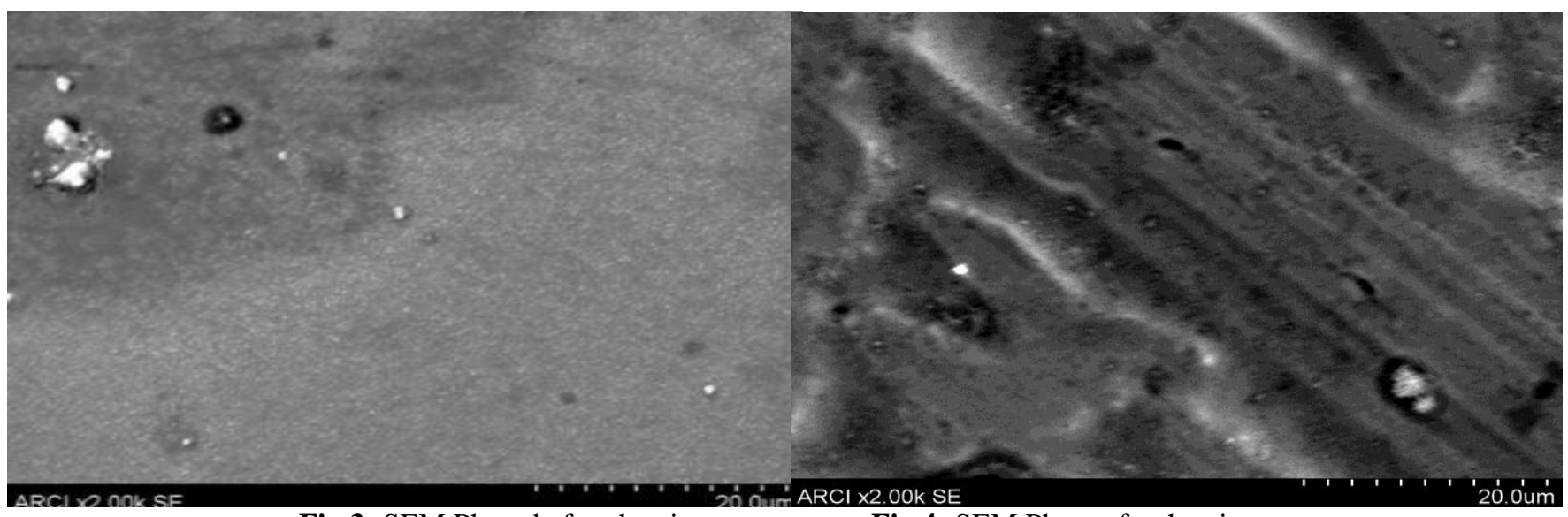

Fig 3: SEM Photo before heating

Fig 4: SEM Photo after heating

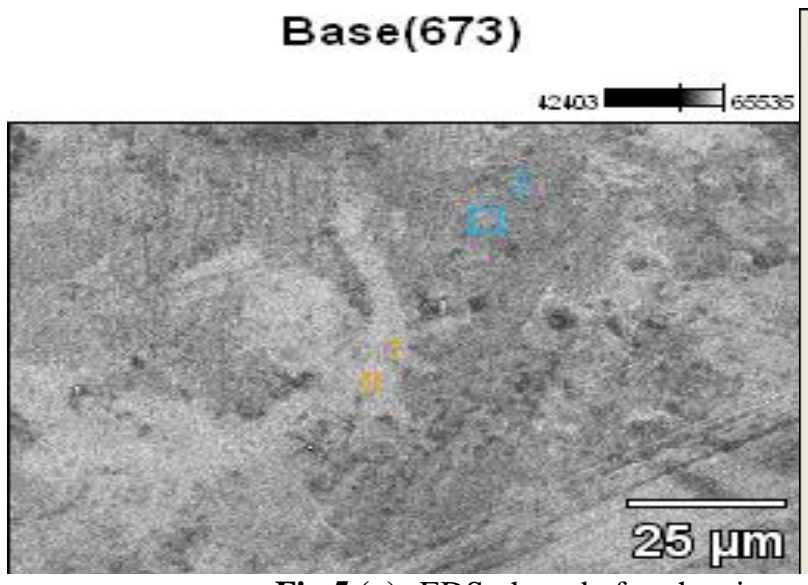

Fig 5 (a): EDS photo before heating

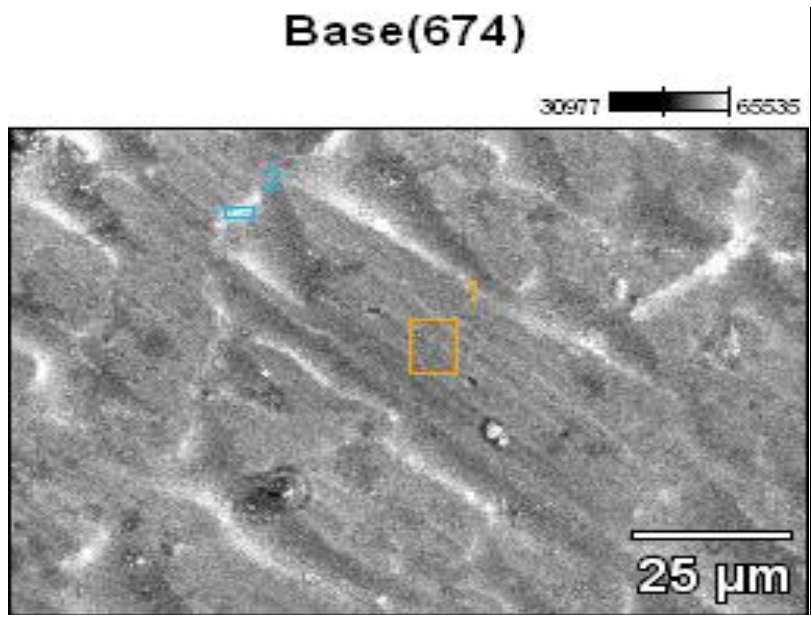

Fig 6(a): EDS photo after heating

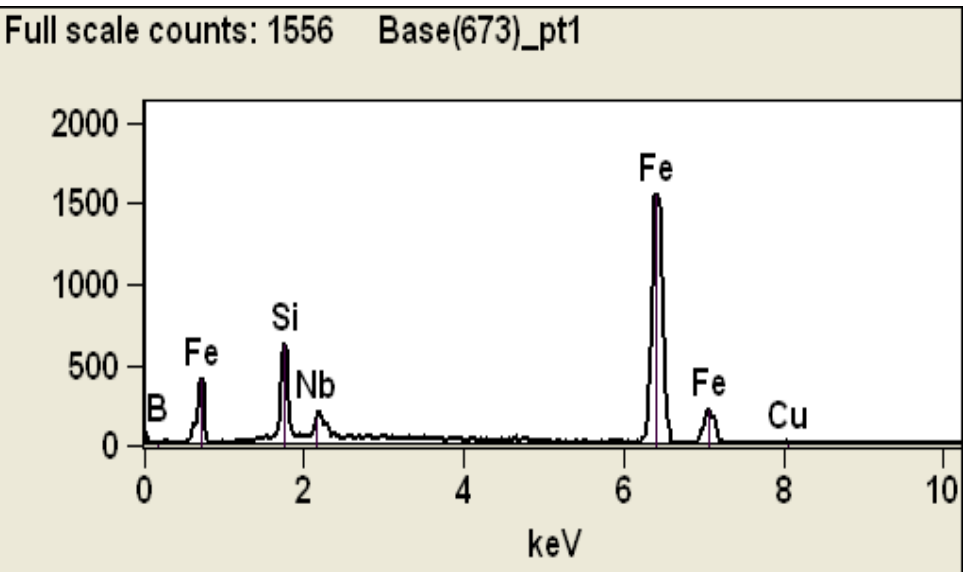

Fig 5(b): EDS Spectrum before heating

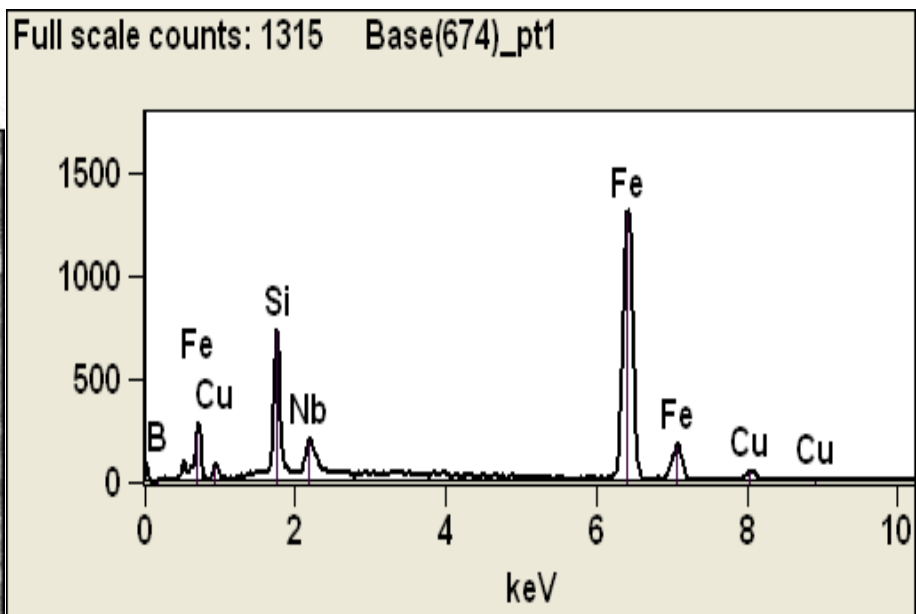

Fig 6(b): EDS spectrum after heating 
The resistance versus temperature curve of amorphous $\mathrm{Fe}_{78}$ $\mathrm{Gd}_{2} \mathrm{~B}_{20}$ alloy showed a drop at about $803 \mathrm{~K}$ due to massive nucleation and growth of a primary crystalline phase. An exothermal peak was observed at $828 \mathrm{~K}$ in the differential scanning calorimetry (DSC) curve for this alloy. From the DSC, the crystallization temperature of $\mathrm{Fe}_{78} \mathrm{Gd}_{2} \mathrm{~B}_{20}$ alloy was found to be $828 \mathrm{~K}$. The fresh amorphous sample annealed at $825 \mathrm{~K}$ for one hour confirmed the crystallization of the sample. The primary phase from XRD in this crystallized sample is found to be $\alpha$ - Fe(Alpha Fe). Also, the lattice parameter ' $a$ ' of the crystallized sample was found to be $2.8656 \mathrm{~A}^{0}$.

From the DSC study the crystallization temperature of $\mathrm{Fe}_{78} \mathrm{Dy}_{2} \mathrm{~B}_{20}$ alloy was found to be $828 \mathrm{~K}$. XRD on the annealed sample at $850 \mathrm{~K}$ for about one hour showed the presence of $\alpha-\mathrm{Fe}$.

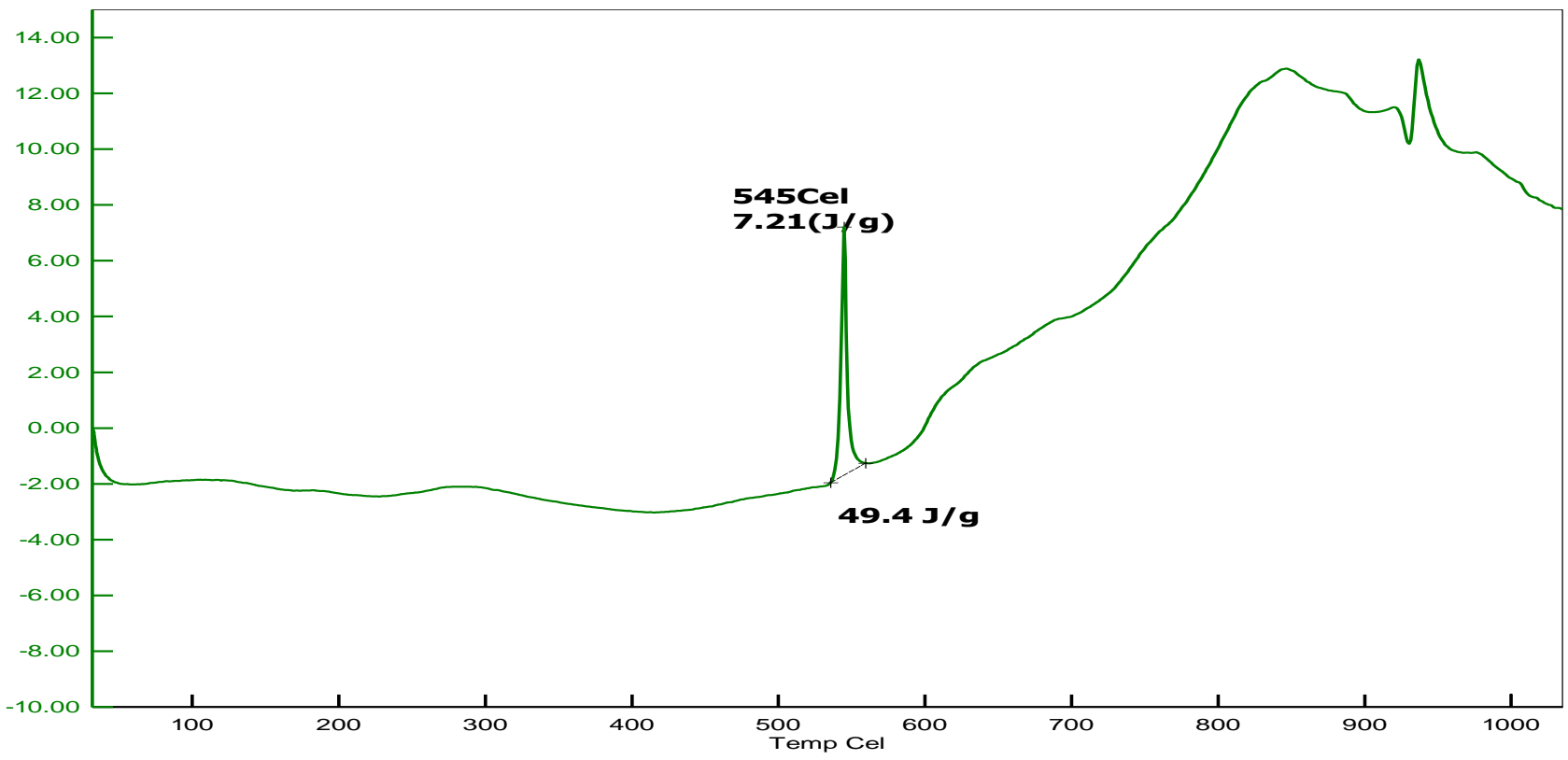

Fig 7 DSC curve of Amorphous $\mathrm{Fe}_{78} \mathrm{Tm}_{2} \mathrm{~B}_{20}$ alloy at a heating rate of $20^{\circ} \mathrm{C} / \mathrm{min}$.

Figure 7 shows the DSC curve of fresh amorphous $\mathrm{Fe}_{78} \mathrm{Tm}_{2} \mathrm{~B}_{20}$ alloy in the temperature range $30^{\circ} \mathrm{C}-1000^{\circ} \mathrm{C}$ at a heating rate of $20^{\circ} \mathrm{C} / \mathrm{min}$. The DSC curve shows a sharp peak at $545^{\circ} \mathrm{C}$ and a broad hump with a small sharp peak in the temperature range $800^{\circ} \mathrm{C}-1000^{\circ} \mathrm{C}$. The first sharp peak at $545^{\circ} \mathrm{C}$ shows phase transformation from amorphous to crystalline indicating the primary crystallization of the amorphous sample where a primary crystalline phase $\alpha$-Fe grows in the amorphous matrix. The broader curve with a small sharp peak may indicate secondary crystallization of the sample after which the sample is completely crystallized. A detailed study on the confirmation of the phases in the primary and secondary crystallization of the sample will be reported later.

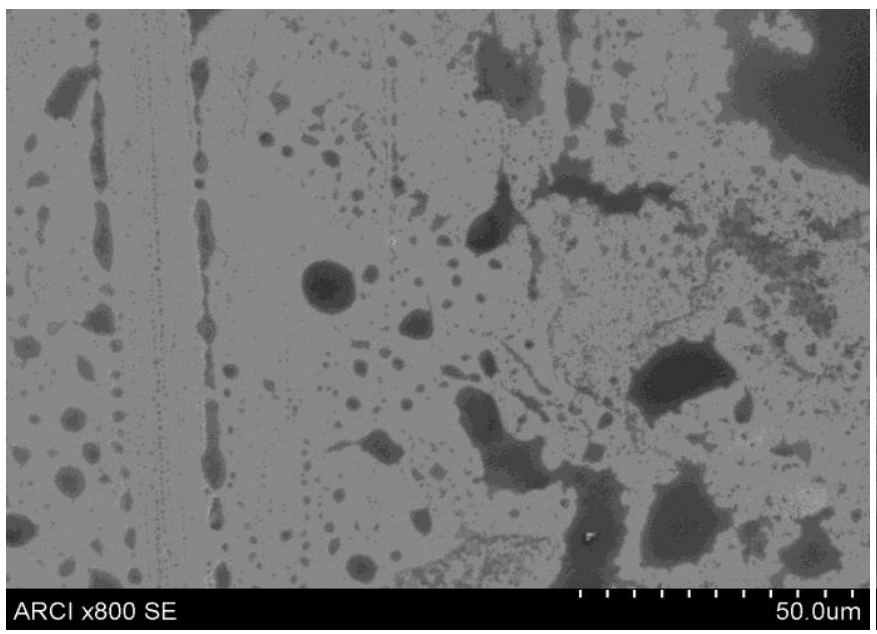

Fig. 8 SEM photo of as cast sample

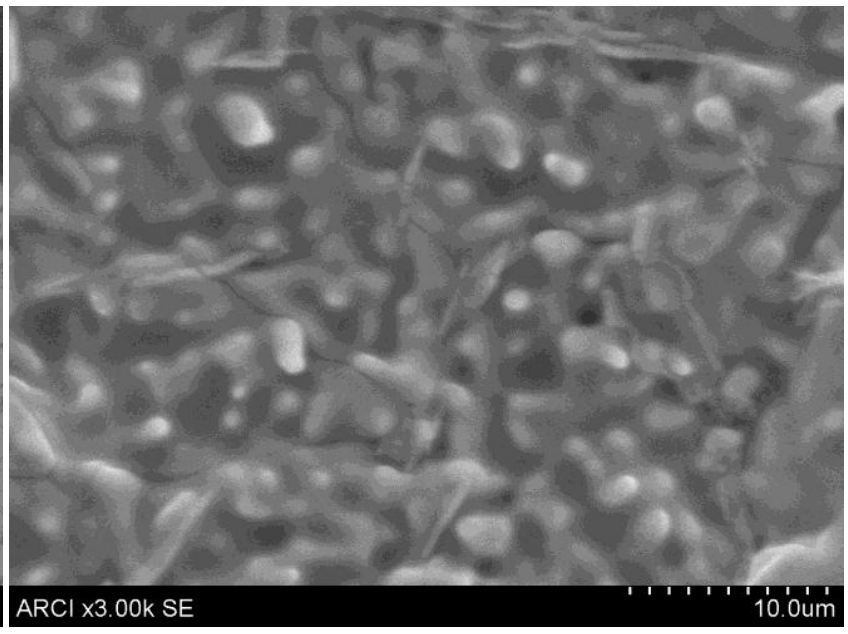

Fig. 9 SEM photo of heated sample 
Figures 8 and 9 show SEM micrographs of as cast and heated samples. EDS studies were performed to identify elements present in the sample before and after heating.
Thus, Figs. 4 and 5 show the EDS photo and spectrum of the sample before heating. Similarly, Figs. 6 and 7 show the EDS photo and spectrum of the sample after heating.

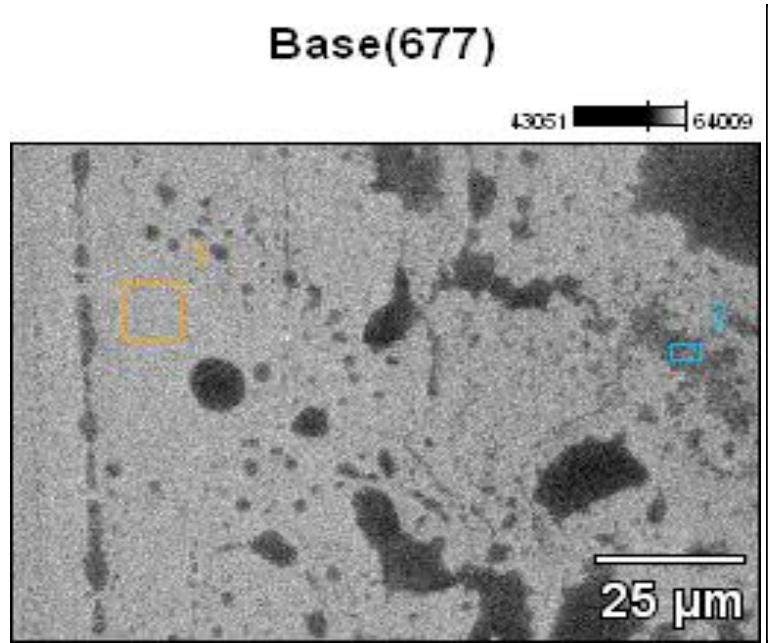

Fig. 10 EDS photo of the sample

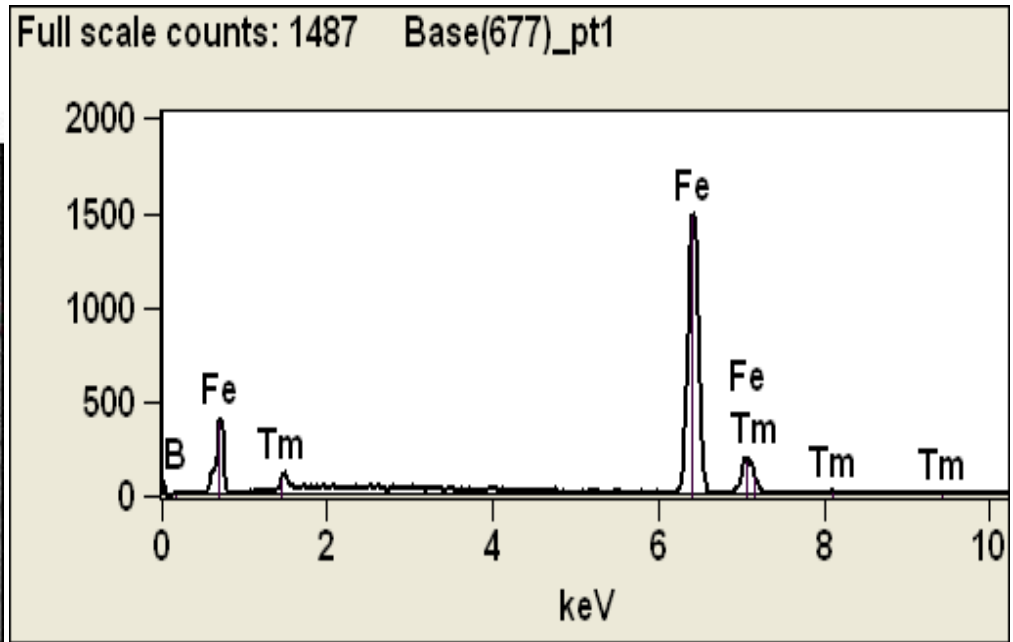

Fig. 11 EDS spectrum of the sample before heating before heating

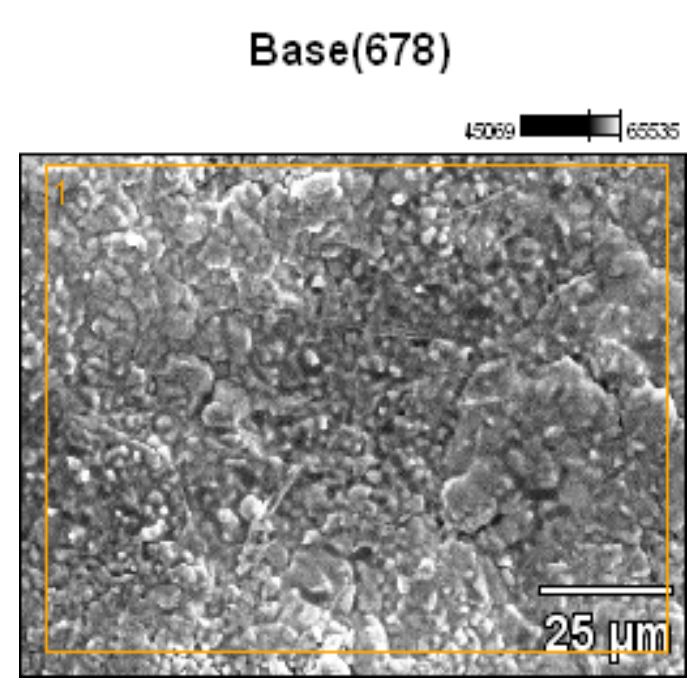

Fig. 12 EDS photo after heating

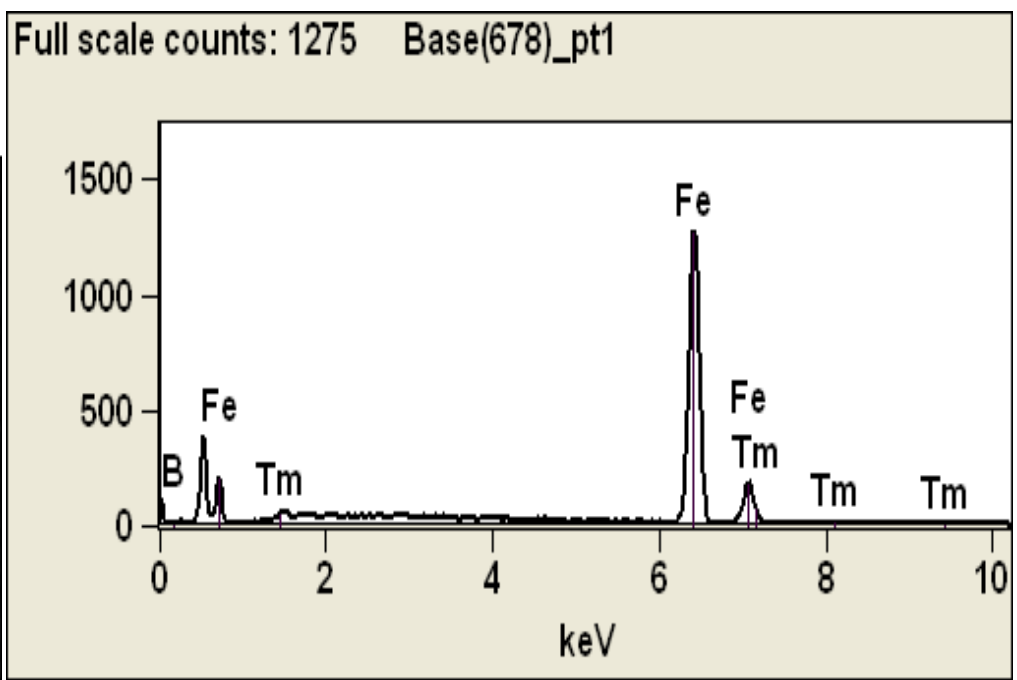

Fig. 13 EDS spectrum after heating
SEM and EDS of heated sample show that the amorphous sample is crystallized after heating to $1000^{\circ} \mathrm{C}$.

\section{CONCLUSION}

DSC of amorphous $\mathrm{Fe}_{68.8} \mathrm{Si}_{18.6} \mathrm{~B}_{9.5} \mathrm{Nb}_{2.6} \mathrm{Cu}_{0.5}$ alloy showed two peaks one at $569^{\circ} \mathrm{C}$ and another at $709^{\circ} \mathrm{C}$ respectively indicating two step crystallization. XRD of the crystallized samples showed the presence of the crystalline phase $\alpha$-Fe. The DSC curve of Amorphous $\mathrm{Fe}_{78} \mathrm{Gd}_{2} \mathrm{~B}_{20}$ alloy showed an exothermal peak at $828 \mathrm{~K}$ showing the crystallization of the sample. From the DSC study, the crystallization temperature of $\mathrm{Fe}_{78} \mathrm{Gd}_{2} \mathrm{~B}_{20}$ alloy was found to be $828 \mathrm{~K}$. The lattice parameter ' $\mathrm{a}$ ' was found to be $2.8656 \mathrm{~A}^{\mathrm{o}}$. From the DSC study the crystallization temperature of $\mathrm{Fe}_{78} \mathrm{Dy}_{2} \mathrm{~B}_{20}$ alloy was found to be $828 \mathrm{~K}$. DSC study on amorphous $\mathrm{Fe}_{78} \mathrm{Tm}_{2} \mathrm{~B}_{20}$ alloy showed a sharp peak at $818 \mathrm{~K}$ indicating a phase transformation from amorphous to crystalline in the sample.

\section{ACKNOWLEDGEMENTS}

The authors would like to thank the Management, Principal and staff of M.V.S.R. Engineering College for continuous encouragement and support in completing the work.

\section{REFERENCES:}

[1]. T. H. Noh, M. B. Lee, H.J. Kim, I.K. Kang, J. Appl. Phys. 67(1990) 5568.

[2]. Y. Yoshizawa, S. Oguma, K. Yamauchi. J. Appl. Phys. 64(1988)6044.

[3]. Y.R. Zhang and R.V. Ramanujan : Intermetallics , 2006 , 14710 .

[4]. Panda A K, Ravikumar B, Basu.S and Mitra.A 2003 J.Magn. Matter. 26070. 